\title{
ASPECTOS CULTURAIS E METODOLÓGICOS NO PROCESSO DE APRENDIZAGEM DOS ESTUDANTES INDÍGENAS MACUXI: EXPERIÊNCIAS DO INSTITUTO FEDERAL DE RORAIMA CAMPUS AMAJARI
}

\author{
Maria Aparecida Xavier Silva ${ }^{1}$ \\ Lediane Fani Felzke ${ }^{2}$
}

\section{RESUMO}

O presente artigo tem como objetivo compreender aspectos sobre como os indígenas constroem o conhecimento e dialogam os saberes indígenas e não indígenas no processo de ensino-aprendizagem na Educação Profissional e Tecnológica. Para isso, foi desenvolvida uma pesquisa participante que contou com o envolvimento de 21 estudantes indígenas da etnia Macuxi que estavam cursando o terceiro ano do curso Técnico em Agropecuária Integrado ao Ensino Médio em Regime de Alternância do Instituto Federal de Roraima/Campus Amajari. O estudo revelou que o processo de ensino e aprendizagem tornase mais significativo quando os docentes buscam aproximar as disciplinas, ofertadas pelo curso, dos saberes tradicionais dos estudantes indígenas. Contudo os estudantes argumentam que são poucos os professores que têm essa preocupação de contextualizar os conteúdos ensinados com a vivência do dia a dia. Com isso, conclui-se, que o Campus precisa possibilitar estratégias que valorizem os saberes prévios dos estudantes no ensino de novos conteúdos ofertados durante o curso.

Palavras- Chaves: Educação Profissional e Tecnológica; Ensino e aprendizagem; Estudantes Macuxi; Saberes indígenas.

\section{CULTURAL AND METHODOLOGICAL ASPECTS IN THE LEARNING PROCESS OF INDIGENOUS STUDENTS: EXPERIENCES OF THE FEDERAL INSTITUTE OF RORAIMA CAMPUS AMAJARI}

\begin{abstract}
This article aims to understand aspects about how indigenous people build knowledge and dialogue with indigenous and non-indigenous knowledge in the teaching-learning process in Professional and Technological Education. For this, a participant research was carried out with the involvement of 21 indigenous students of the Macuxi ethnicity who were taking the third year of the Technical course in Agricultural Integrated to High School in Alternation Regime at the Federal Institute of Roraima / Campus Amajari. The study revealed that the
\end{abstract}

\footnotetext{
${ }^{1}$ Instituto Federal de Educação, Ciência e Tecnologia de Roraima/IFRR-Email:xavieruniversitaria@gmail.com

${ }^{2}$ Instituto Federal de Educação, Ciência e Tecnologia de Rondônia/IFRO- Email:lediane.fani@ifro.edu.br
} 
teaching and learning process becomes more significant when teachers seek to bring the disciplines offered by the course closer to the traditional knowledge of indigenous students. However, students argue that few teachers have this concern to contextualize the contents taught with their daily experience. With that, it is concluded, that the Campus needs to enable strategies that value the previous knowledge of the students in the teaching of new contents offered during the course.

Keywords: Professional and Technological Education; Teaching and learning; Macuxi students; Indigenous knowledge.

\section{INTRODUÇÃO}

A escola para os povos ameríndios é a mais antiga do Brasil e as primeiras ações escolares são da época colonial. Ao fazer uso das terras povoadas pelos povos indígenas, uma das primeiras atitudes dos europeus foi ordenar e impor aos indígenas um mecanismo educativo de acordo com os padrões ocidentais, sendo a escola um deles (BERGAMASCHI; SILVA, 2007). Assim, a história da educação escolar entre os povos indígenas esteve fundada em diferentes perspectivas, a primeira delas remete à época colonial, em que o sistema educacional estava nas mãos dos missionários jesuítas e tinha como principal propósito a rejeição da diversidade dos indígenas. A segunda é marcada pela criação do Serviço de Proteção aos Índios (SPI), em 1910, e se estende até os anos 1970. Segundo Nascimento (2017), neste tempo o estado tinha resolvido formular uma política indigenista menos desumana, já que havia uma expressa preocupação com a diversidade linguística e cultural dos povos indígenas do país.

Contudo, ao passar dos anos, uma série de acontecimentos contribuiu para que no início dos anos 1970 começassem a surgir no contexto político nacional Organizações Não Governamentais (ONGs) voltadas para a defesa da causa indígena. E a partir de então "[...] uma série de ONGs passou a questionar o modelo educacional homogeneizador destinado às populações indígenas e começou a desenvolver experiências inovadoras com educação escolar junto a essas coletividades” (NASCIMENTO, 2017, p.31). Porém, era indispensável o reconhecimento desses povos e especialmente a garantia da preservação de suas formas específicas de viver e de pensar. Esse reconhecimento veio se consagrar com a promulgação da Constituição Federal (CF) de 1988, momento em que o país viveu o ápice das lutas iniciadas na década de 1970, dando início a um período de inquietação por parte do 
movimento indígena e indigenista. Com isso, a educação específica reivindicada pelos povos indígenas passou a ganhar ainda mais força com a publicação de outras legislações a nível nacional que também reconheceram o direito dos indígenas a uma educação escolar diferenciada, intercultural e bilíngue. Tais legislações como a Lei de Diretrizes e Base da Educação Nacional (LDBEN) de 1996, Parâmetros Curriculares Nacionais (PCNs) e o Plano Nacional de Educação (PNE) preconizam como dever do Estado o desenvolvimento de programas integrados de ensino e pesquisa, para oferta de educação escolar bilíngue e intercultural aos povos indígenas.

Diante dessa conjuntura, este artigo se propõe a refletir sobre instituições escolares não indígenas que atendem estudantes indígenas, e o que elas têm feito para aproximar-se de uma educação escolar intercultural, como é o caso do Instituto Federal de Educação, Ciência e Tecnologia de Roraima que iniciou a oferta de Educação Profissional e Tecnológica em 08/12/2010, dentro dos pressupostos do Plano de Expansão da Educação Tecnológica.

\section{A EPT, formação humana e a interculturalidade}

A Educação Profissional e Tecnológica (EPT), ao longo da história, esteve firmada em diferentes concepções entre elas estão o assistencialismo e a preparação de operários para o exercício profissional (MOURA, 2007).

Contudo, a EPT chega à primeira década do século XXI, assumindo uma postura mais progressista no campo da educação, tendo em vista à composição de um governo democrático-popular; buscando promover o desenvolvimento do país por meio da oferta de ensino, pesquisa e extensão à população em sintonia com as demandas dos Arranjos Produtivos Locais (TAVARES, 2012). Nessa nova concepção, o estado apresenta - em suas diretrizes - uma proposta de educação integral, que aproxima e integra conhecimentos gerais e específicos.

A partir de então, surge a ideia de formação integrada que sugere superar o ser humano dividido historicamente pela divisão social do trabalho entre a ação de executar e a ação de pensar, dirigir ou planejar (RAMOS, 2014). E o caminho para a superação dessa dualidade seria uma formação humana que garantisse uma leitura de mundo capaz de permitir uma atuação como cidadão, compreendendo sua responsabilidade em uma sociedade em constante transformação (OLIVEIRA, 2019). Para a compreensão da formação humana, 
Ramos (2001) apresenta dois pressupostos. O primeiro deles é compreender que homens e mulheres são seres histórico-sociais, que atuam no mundo concreto para satisfazerem suas necessidades subjetivas e sociais e, nessa ação, produzem conhecimentos. O segundo é que a realidade concreta é uma totalidade, síntese de múltiplas relações. Assim:

Desses pressupostos decorre um princípio de ordem epistemológica, que consiste em compreender o conhecimento como uma produção do pensamento pela qual se apreende e se representam as relações que constituem e estruturam a realidade objetiva. Apreender e determinar essas relações exige um método, que parte do concreto empírico - forma como a realidade se manifesta - e, mediante uma determinação mais precisa através da análise, chega a relações gerais que são determinantes da realidade concreta. O processo de conhecimento implica, após a análise, elaborar a síntese que representa o concreto, agora como uma reprodução do pensamento conduzido pelas determinações que o constituem (RAMOS, 2014, p. 86)

A partir dessa compreensão, Ramos (2014) ressalta que a integração expressando uma concepção de formação humana, com base na integração de todas as dimensões da vida no processo educativo, visa à formação omnilateral dos sujeitos. Essas dimensões são constituídas pelo trabalho, a ciência e a cultura. Com isso, ao assumir a formação integral do cidadão, a Educação Profissional e Tecnológica passa também a considerar a diversidade e a inclusão social.

Em 1988, a Constituição Federal reconheceu a característica multiétnica, pluricultural e multilíngue da população brasileira. Como efeito, políticas públicas na área educativa precisaram contemplar as diferenças culturais. Dessa forma, “[...] as diferentes reformas na área de educação incorporam a perspectiva intercultural, seja como um dos eixos articuladores dos currículos escolares, seja introduzindo questões relativas às diferenças culturais como temas transversais" (CANDAU; RUSSO, 2010, p.163).

Ainda nesse sentido, Fleuri (2003) discorre que, desde o lançamento dos Parâmetros Curriculares Nacionais, que elegeram a pluralidade cultural como um dos temas transversais, o reconhecimento da multiculturalidade e a perspectiva intercultural ganharam grande relevância social e educacional. No entanto, o termo 'intercultural' tem sido usado para manifestar realidades e concepções muitas vezes inadequadas no ambiente educacional. Nessa perspectiva, a discussão da interculturalidade, neste trabalho, gira em torno da concepção 
defendida por Fleuri (2003), a qual afirma que a interculturalidade deve ser compreendida como possibilidade de respeitar as diferenças e integrá-las em uma unidade que não as anule.

Assim, no contexto da Educação Profissional e Tecnológica em que exista a presença de vários grupos étnicos, o trabalho intercultural deve "[...] contribuir para superar tanto a atitude de medo quanto a de indiferente tolerância ante o 'outro', construindo uma disponibilidade para a leitura positiva da pluralidade social e cultural" (FLEURI, 2003, p. 17). A partir dessa leitura, refletimos sobre a escola enquanto lugar de diálogo e relação entre povos, em que existe curso de gente e informação e onde as diversidades comunitárias são produzidas (TASSINARI, 2001).

\section{PERCURSO METODOLÓGICO}

O estudo que serviu de base para a construção deste trabalho foi realizado por meio da pesquisa participante. A escolha se deve ao fato deste buscar o envolvimento dos colaboradores na análise de sua própria realidade e se desenvolver a partir da interação entre as pesquisadoras e os membros da situação investigada. Participaram da pesquisa os estudantes do curso Técnico em Agropecuária Integrado ao Ensino médio em Regime de Alternância do IFRR/CAM, que estavam no último ano do curso em 2019.

Ao lançar mão dessa metodologia, a intenção era conhecer e compreender as diversidades que permeiam a vida acadêmica dos estudantes Macuxi dentro da sistemática de ensino ofertado pelo IFRR/Campus Amajari, permitindo que os estudantes relatassem suas experiências/vivências e compreensões a respeito dos aspectos culturais e metodológicos que transpassam o processo de ensino/aprendizagem. Nessa perspectiva, a pesquisa participante “[...] apresenta-se como uma alternativa de ação participante [...] agentes sociais populares são considerados mais do que beneficiários [...] porque ela se projeta e realiza desdobres através da participação ativa e crescente de tais atores" (BRANDÃO; STRECK 2006, p. 28). Desse modo, os questionamentos de pesquisa participante visam à colaboração em processos mais abrangentes e sucessivos de construção progressiva de um saber mais partilhado, mais amplo e mais sensível às origens do entendimento popular (BRANDÃO; BORGES, 2007).

Para a análise e interpretação dos dados produzidos, utilizamos parte das perspectivas de análise de conteúdo defendida por (BARDIN, 1977). Segundo a autora, a análise de 
conteúdos passa por algumas fases: “1) a pré-análise; 2) a exploração do material; 3) o tratamento dos resultados, a inferência e a interpretação".

Como instrumentos de construção dos dados, utilizamos questionário com questões abertas e rodas de conversa. O questionário como instrumento visou conhecer a identidade dos estudantes indígenas que cursavam o curso Técnico em Agropecuária Integrado ao Ensino Médio em regime de Alternância, como também a perspectiva destes acerca das contribuições dos saberes indígenas para o aperfeiçoamento das práticas pedagógicas desenvolvidas durante o curso. Esta ferramenta composta por dez questões abertas possibilitou aos participantes responder livremente, usando linguagem própria e emitindo opiniões. Richardson (2008, p.192) reforça que "[...] perguntas abertas caracterizam-se por perguntas ou afirmações que levam o entrevistado a responder com frases ou orações. O pesquisador não está interessado em antecipar as respostas, deseja uma maior elaboração das opiniões do entrevistado".

As rodas de conversa buscaram investigar as contribuições e mudanças provocadas nos estudantes indígenas a partir da execução do currículo e compreender como os estudantes indígenas constroem o conhecimento e dialogam os saberes indígenas e não indígenas no processo de ensino-aprendizagem. Como técnica de pesquisa, as rodas de conversa tiveram como objetivo abrir espaço para que os participantes da pesquisa, através do diálogo e interação ampliassem suas percepções sobre si e sobre o outro no dia a dia escolar, pois "[...] a investigação de um fenômeno social é um desafio maior do que a investigação de um objeto físico à medida que se busca compreender uma realidade da qual o ser humano é agente" (MELO; CRUZ, 2014, p. 32).

As rodas de conversa foram conduzidas a partir de um roteiro, por meio do qual os estudantes puderam manifestar suas percepções acerca de aspectos referentes às contribuições e mudanças provocadas na vida acadêmica a partir da execução do currículo do curso ofertado pelo IFRR/Campus Amajari e como eles compreendem o processo, constroem o conhecimento e dialogam os saberes indígenas e não indígenas no processo de ensinoaprendizagem.

\section{RESULTADO E DISCUSSÃO}

Inicialmente, buscamos através do questionário, conhecer a identidade dos estudantes indígenas que cursavam o curso Técnico em Agropecuária em Regime de Alternância e, em 
seguida, levantar as contribuições que os saberes indígenas trazem para o aperfeiçoamento das práticas pedagógicas desenvolvidas no curso Técnico em Agropecuária em Regime de Alternância.

Antes de realizar a entrega do questionário aos estudantes indígenas, buscamos junto à Coordenação de Registros Escolares (CORES) alguns dados preliminares que subsidiaram a compreensão dos objetivos propostos. Todos os estudantes participantes da pesquisa se autodeclararam indígenas pertencentes à etnia Macuxi. Estes estudantes são moradores das comunidades do Contão, Cantagalo e Surumu, pertencentes ao município de Pacaraima; Placa e Olho D’água ao município de Normandia e São Luiz ao município de Uiramutã, todos no estado de Roraima e dentro das terras indígenas Raposa Serra do Sol e São Marcos. No entanto, apesar de a turma ter sido formada com alguns membros de comunidades adjacentes à do Contão, os estudantes se identificam como a turma do Contão. A seguir o mapa do estado de Roraima e local de origem dos estudantes.

Mapa 01 - Estado de Roraima/Local de origem dos estudantes

\section{ESTADO DE RORAIMA/LOCAL DE ORIGEM DOS ESTUDANTES}
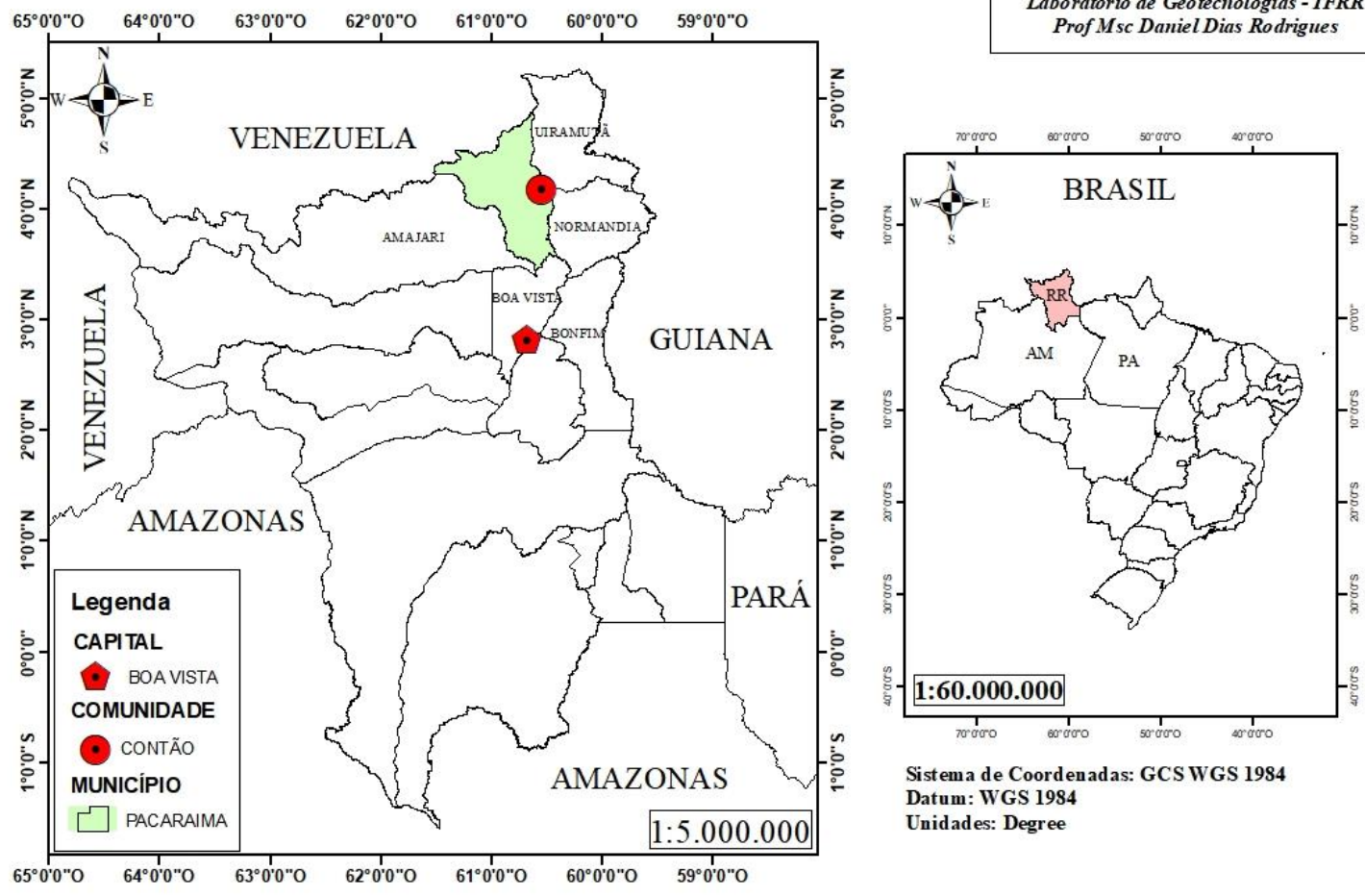

Sistema de Coordenadas: GCS WGS 1984

Datum: WGS 1984

Unidades: Degree

A turma foi formada por 31 alunos. Desses, 21 eram meninos - o que corresponde $67 \%$ da turma, e 10 meninas correspondendo 33\%. Estes alunos são oriundos da Escola 
Estadual Indígena José Marcolino, localizada na comunidade do Contão, município de Pacaraima no noroeste do estado de Roraima. Muitos desses estudantes saíram pela primeira vez de suas casas deixando seus familiares em busca de novos conhecimentos.

Cabe ressaltar que os participantes da pesquisa fazem parte da segunda turma do curso Técnico em Agropecuária em Regime de Alternância. Em 2014, já havia sido ofertada uma turma. E, no primeiro semestre de 2020, iniciou-se a terceira. A partir dessas turmas, verificamos que, na oferta do curso Técnico em Agropecuária em Regime de Alternância, a presença de estudantes indígenas se mostra mais acentuada em relação ao quantitativo geral no Campus. O quadro a seguir evidencia esses dados.

Quadro 01 - Curso Técnico em Agropecuária Integrado ao Ensino Médio em Regime de Alternância

\begin{tabular}{|l|l|l|}
\hline Turmas & Quant. de alunos/turma & $\begin{array}{l}\text { Porcentagem de estudantes que se } \\
\text { autodeclaram indígenas }\end{array}$ \\
\hline $1^{\mathbf{o}}$ Turma & 32 & Não obtivemos dados precisos \\
\hline $2^{\mathbf{o}}$ Turma & 31 & $90,32 \%$ \\
\hline $3^{\mathbf{0}}$ Turma & 29 & $82,75 \%$ \\
\hline
\end{tabular}

Fonte: Sistema Unificado de Administração Pública/SUAP/IFRR/Campus Amajari.

Os números se justificam porque as turmas em Regime de Alternância são formadas a partir de demandas comunitárias, que - em reuniões com a gestão do Campus - levantam a necessidade de formação de seus jovens. Isso vai ao encontro da proposta pedagógica do curso de contribuir com a formação dos jovens das comunidades da região. Diante dessas informações preliminares, apresentaremos os dados construídos com a aplicação do questionário. Após a pré-análise do questionário, as perguntas foram divididas em categorias e estas são apresentadas nos quadros que se seguem. No primeiro quadro, são apresentados os questionamentos que buscaram conhecer a identidade dos estudantes indígena que cursavam o curso Técnico em Agropecuária em Regime de Alternância. As temáticas abordadas com os estudantes foram: motivação, dificuldades e desafios enfrentados.

Quadro 02 - Motivação, dificuldades e desafios enfrentados no Campus Amajari.

\begin{tabular}{|l|l|}
\hline Questão-01 & Por que você decidiu vir estudar no IFRR/Campus Amajari? Escreva um \\
\hline
\end{tabular}




\begin{tabular}{|l|l|}
\hline & pouco sobre o que motivou a vir estudar no Campus. \\
\hline Questão-02 & $\begin{array}{l}\text { Ao iniciar o curso, você sentiu muita dificuldade de acompanhar os } \\
\text { conteúdos que eram ensinados? Fale um pouco sobre as suas dificuldades e } \\
\text { facilidades encontradas no desenvolvimento das disciplinas. }\end{array}$ \\
\hline Questão-03 & $\begin{array}{l}\text { O que é diferente no ensino ofertado pelo IFRR/Campus Amajari e o ensino } \\
\text { que você recebeu na escola anterior em que estudou? O que você acha que o } \\
\text { IFRR deveria fazer para que os alunos pudessem aprender com mais } \\
\text { facilidade? }\end{array}$ \\
\hline
\end{tabular}

Fonte: Elaboração própria a partir do questionário.

A primeira pergunta foi respondida por 17 (dezessete) estudantes de um grupo de 21 (vinte e um). Após a análise das respostas, obteve-se o seguinte resultado: 65\% dos estudantes responderam que a decisão de estudar no IFRR/Campus Amajari partiu da motivação dos pais, pois os estudos na comunidade estavam muito fracos e o curso poderia proporcionar novos conhecimentos, além de poder contribuir com o desenvolvimento da comunidade; $24 \%$ atribui a ida para Campus ao fato da instituição ofertar ensino de qualidade e possuir uma boa estrutura, além de professores qualificados; $6 \%$ a afeição por animais como sendo decisivo na decisão e $6 \%$ se justificou por ser oriundo de área indígena, o curso poderia auxiliar na lida com a terra. A partir das justificativas, percebemos que os estudantes realizaram uma comparação entre o ensino da comunidade e o ofertado pelo Campus ao afirmarem que "os estudos na comunidade estavam muito fracos", é possível que essa comparação esteja atrelada não apenas a defasagem que possa existir na escola indígena, mas também ao fato de que o Campus Amajari não trabalha os princípios da interculturalidade, ou seja, não parte dos conhecimentos tradicionais considerando a diversidade.

A motivação dos pais foi à razão apontada por $65 \%$ dos estudantes que cursavam o curso Técnico em Agropecuária Integrado ao Ensino Médio em Regime de Alternância no IFRR/CAM, 2019. Essa tendência pode ser percebida na afirmação dos estudantes, a seguir algumas dessas falas:

"Eu decidir estudar no Campus Amajari pelos meus pais, eles me motivaram por que lá na comunidade o desempenho estava fraco de mais [...]” (PK, 2019).

"Bom eu vim mais por curiosidade [...] e motivação de minha mãe e meus amigos" (PB, 2019). 
"Motivação dos pais, e o curso que é Técnico em Agropecuária” (PD, 2019).

Como já mencionado, a proposta pedagógica do curso afirma que a oferta do curso surge a partir de demandas da comunidade, o que acarreta o fato de a família ser a motivação de boa parte dos estudantes que decidem estudar no Campus Amajari tendo nisso seu lado positivo. Pois, isso demonstra a credibilidade que muitas famílias depositam na instituição através da oferta de cursos técnicos. Contudo, existem também pontos negativos, entre eles, estão casos de alunos que chegam à escola e não se identificam com o curso, porém continuam a frequentar as aulas, apenas para não decepcionar seus pais/famílias. Isso acarreta um grande desafio na busca pela permanência e êxito desses alunos por parte da gestão, professores e técnicos envolvidos no processo de ensino e aprendizagem.

A segunda pergunta quis saber quais as dificuldades e facilidades encontradas no início do curso em relação ao ensino dos conteúdos propostos. Os estudantes apontaram vários fatores, dentre eles: dificuldades na área de ciências exatas (matemática, física, química) e em língua portuguesa; adaptação ao ritmo de estudo; quantidade de atividades; disciplinas técnicas. A questão foi respondida por 21 estudantes de um universo de 21. Desse total, 53\% disseram ter tido muita dificuldade na área de exatas; $24 \%$ alegaram dificuldades em adaptação, pois nunca tinham estudado o dia inteiro; $15 \%$ disseram que sentiram dificuldades em acompanhar as disciplinas técnicas do curso; $10 \%$ expuseram o excesso de atividades, não conseguindo acompanhar. A partir desses relatos e análise do PPC, entendemos que existe uma distância entre os princípios da interculturalidade e a proposta pedagógica do curso o que contribui para as dificuldades enfrentadas, pois no processo de ensino de estudantes indígenas é primordial que haja um olhar sensível às diversidades e especificidades que permeiam os aspectos de aprendizagem.

Com relação à pergunta sobre "facilidades encontradas", apenas, um estudante escreveu:

"A facilidade é que consegui assimilar o que os professores nos repassavam, pois os professores tinham uma metodologia de ensino diferente da minha antiga escola” $(P R, 2019)$.

Sobre as dificuldades apontadas por 53\% dos estudantes, segundo Barros (2013), isso se justifica pela carência de profissionais qualificados nas diversas áreas e disciplinas nas comunidades indígenas. Contudo, essa problemática vai além da falta de professores qualificados nas comunidades. Como já abordamos, existe uma lacuna entre a educação 
escolar indígena intercultural, diferenciada e o curso ofertado pelo Campus Amajari e, quando falamos especificamente do grupo de disciplinas (matemática, física e química), o que é proposto se apresenta muito distante da vivência desses estudantes. E, diante disso, os alunos acabam atrelando as dificuldades ao fato de não terem tido professores especializados. Nessa direção, afirmaram os alunos:

"O que eu mais senti dificuldade foi na disciplina de matemática, porque na minha comunidade não tinha professor especializado para essa área [...]” (PI, 2019).

"As dificuldades que eu tive foi por conta da escola que eu estudei antes de vim para cá que não tinha professor de matemática, fisica e química" (PD, 2019).

As respostas à terceira pergunta: "O que é diferente no ensino ofertado pelo IFRR/Campus Amajari e o ensino que receberam na escola anterior? O que você acha que o IFRR deveria fazer para que os alunos pudessem aprender com mais facilidade?", apresentaram-se em maior número, assim optamos, após a análise, por trazer aquelas que mais apareceram nas respostas dos estudantes. Posto isso, 24\% disseram que a principal diferença era a metodologia dos professores; $19 \%$ disseram que a maior diferença era que no Campus não havia falta de professores como na escola anterior; e 19\% afirmaram que o estudo de matérias de campo tais como "Forragicultura, Fertilidade do solo e nutrição de plantas, Irrigação e drenagem entre outras", que nunca haviam visto anteriormente, era a maior diferença. A diferença metodológica apontada por $24 \%$ dos estudantes nos leva a reafirmar a necessidade de aproximar as práticas pedagógicas desenvolvidas no curso de uma prática intercultural, em que os estudantes encontrem sentido entre sua realidade e o que o curso ofertado e, desta forma, possa construir e reconstruir novos conhecimentos.

No que diz respeito à pergunta "O que você acha que o IFRR deveria fazer para que os alunos pudessem aprender com mais facilidade?”, as respostas também foram diversas. Eles expressaram que os professores poderiam realizar mais visitas técnicas em que os alunos pudessem presenciar o que está sendo estudando em sala de aula; diversificar os métodos de dar aula; motivar os alunos com esporte; ofertar palestras sobre métodos de estudo; colocar o aluno para manusear "algo técnico", dar instrução. Abaixo algumas falas dos estudantes:

"A diferencia está no método de aula em que o professor passava e no método novo que eu tive que me acostumar e conhecer. O IFRR poderia oferecer outros métodos de aula" (PT, 2019). 
"A diferença é incomparável, porque na minha escola eu estudava e aprendia apenas o básico do básico. Mas, aqui no IFRR conheci disciplinas que eu nunca imaginava conhecer, é uma escola que ajuda muito o aluno a se preparar para coisas e casos alternativos" (PP, 2019).

"Diferente do ensino daqui são as matérias técnicas, professores qualificados e lá na comunidade era apenas o básico que alguém poderia ver” (PK, 2019).

"O conhecimento ofertado no Campus Amajari é muito avançado. Poderia ser feito mais visitas técnicas a lugares que ajudaria o aluno presenciar o que estava sendo estudado” (PH, 2019).

"Na escola anterior quase não tinha professores para ensinar. E aqui no IFRR temos professores qualificados, e isso nos ajuda muito no ensino” (PC, 2019).

"A diferença é que na comunidade chamamos as matérias de disciplinas e, agora no instituto é conhecido como componente curricular, e também as aulas que anteriormente eram apenas dentro de sala de aula e no IFRR temos aula de campo" (PF, 2019).

A partir dessas três questões, verificamos que esses estudantes - em sua maioria decidiram cursar o curso Técnico em Agropecuária, motivados pelos pais. Estes estudantes apresentaram dificuldades no acompanhamento de vários componentes curriculares, principalmente na área de exatas. As respostas à questão três informam, em parte, os motivos das dificuldades apresentadas pelos estudantes, pois - segundo os alunos - a escola na comunidade era carente de professores e de estrutura, conforme analisamos acima. Além disso, vale ressaltar que outros fatores como a barreira linguística e a falta de ensino específico e diversificado, conforme prevê as legislações, são obstáculos que contribuem para os problemas enfrentados. Os alunos apontaram, ainda, a terminologia usada pelos professores como sendo diferente e contribuindo para as dificuldades enfrentadas. Nesse sentido, práticas interculturais que busquem valorizar aspectos da vivência desses alunos podem ser uma aliada neste contexto. E aqui podemos apontar a prática da contextualização que busque considerar a realidade do aluno, o contexto no qual ele está inserido, como também a interdisciplinaridade como estratégias para se aproximar da interculturalidade.

Para compreender o grau de percepção dos estudantes a respeito das contribuições que os saberes indígenas trazem para o aperfeiçoamento das práticas pedagógicas desenvolvidas no curso foram sugeridas sete questões abertas referentes às contribuições dos conhecimentos prévios dos alunos no processo de ensino e aprendizagem e valorização dos saberes indígena no contexto do Campus Amajari. O quadro a seguir apresenta as sete questões: 
Quadro 03 - Culturas e práticas indígenas, valorização dos saberes indígenas no contexto do Campus Amajari

\begin{tabular}{|l|l|}
\hline $\begin{array}{l}\text { Questão- } \\
04\end{array}$ & $\begin{array}{l}\text { Você acredita que se o professor partir dos conhecimentos prévios que vocês já } \\
\text { sabem no ensino dos conteúdos em sala de aula seria mais fácil o processo de } \\
\text { aprendizagem? Cite exemplos. }\end{array}$ \\
\hline $\begin{array}{l}\text { Questão- } \\
05\end{array}$ & $\begin{array}{l}\text { Durante as aulas os professores buscam relacionar exemplos de atividades das } \\
\text { culturas e práticas indígenas para ensinar os conteúdos proposto da disciplina? }\end{array}$ \\
\hline $\begin{array}{l}\text { Questão- } \\
\text { Você acredita que o conhecimento desenvolvido na sua comunidade contribui } \\
\text { para aprendizagem dos conteúdos ensinados no Instituto? Poderia dar um } \\
\text { exemplo? }\end{array}$ \\
\hline $\begin{array}{l}\text { Questão- } \\
\text { Qxiste uma relação dos conhecimentos que você aprendeu com sua família } \\
\text { com os conteúdos que os professores passam em sala de aula? Caso sim, dê } \\
\text { um exemplo? }\end{array}$ & $\begin{array}{l}\text { Você consegue ver a valorização dos conhecimentos indígenas nas atividades } \\
\text { ofertadas pelo Instituto? O que o IFRR poderia fazer para valorizar mais os } \\
\text { conhecimentos indígenas dentro do curso que você está fazendo? }\end{array}$ \\
\hline $\begin{array}{l}\text { Questão- } \\
09\end{array}$ & $\begin{array}{l}\text { Você consegue aproximar os conteúdos ensinados pelos professores no } \\
\text { Instituto com que você já tinha desenvolvido na sua comunidade? }\end{array}$ \\
\hline $\begin{array}{l}\text { Como os ensinamentos da comunidade têm contribuído para sua permanência } \\
\text { no curso? }\end{array}$
\end{tabular}

Fonte: Elaboração própria a partir do questionário.

Após a análise das respostas, obteve-se o seguinte resultado. Na questão 04, 100\% dos alunos responderam que acreditam que sim, se o professor partir dos conhecimentos prévios que eles já sabem no ensino dos conteúdos fica mais fácil o processo de aprendizagem de novos assuntos. Algumas falas abaixo refletem bem essa afirmação:

"Bom eu acredito que sim, na minha visão os professores, hoje, eles estão aqui, vem de uma realidade bem diferente, eles tentam de alguma maneira introduzir na nossa realidade. Seria mais fácil eles fazerem uma roda de conversa para trocamos saberes e experiências com alguns fazeres” (PL, 2019).

"Sim, porque iremos de fato relembrar os nossos conhecimentos. Ex: Rotação de culturas, eu não sabia para que era feito, mas meu pai fazia só que não falava esse nome”(PA, 2019). 
"Sim, porque o professor tendo isso em mente consegue ensinar com mais facilidade ao aluno, onde também o aluno aprende mais rápido tendo diálogo com certos termos técnicos utilizados pelos professores" (PJ, 2019).

A questão 05 procurou saber se durante as aulas os professores buscavam relacionar exemplos de atividades das culturas e práticas indígenas para ensinar os conteúdos proposto da disciplina. Para esta questão, 62\% dos estudantes responderam "às vezes", que são poucos os professores que fazem essa relação entre a cultura e prática indígena e o conteúdo ministrado na disciplina. Para 33\%, sim, os docentes fazem essa associação. E, para 5\%, não é feito essa ligação. Segue alguns relatos:

“Alguns, como a disciplina de língua portuguesa, nos mostrava às vezes como viviam os povos indígenas, ele pedia para nós contar histórias sobre como nós viviam na comunidade, pedia para fazer desenhos etc." (PI, 2019).

"Somente alguns professores" (PB, 2019).

"Isso vem de poucos professores, creio eu que se a maioria fizesse isso com os alunos ia ficar mais fácil de o professor dar aula, pois os discentes iam se soltar mais e responder as perguntas que eles fazem em sala de aula" (PS, 2019).

"Sim o professor busca relacionar exemplos de atividades no campo durante as aulas práticas" (PU, 2019).

"Pelo que vejo não, porque nós indígena aprendemos de uma forma, já as técnicas são bem diferente. Por exemplo: O espaçamento entre planta, coveamento e várias outras técnicas” (PM, 2019).

Mais uma vez, percebemos o distanciamento de procedimentos interculturais, o que nos leva a problematizar em qual princípio tecnológico o curso está sendo oferecido, haja vista que a formação humana apresentada por Ramos (2014) deve considerar a realidade e os saberes construídos historicamente como sendo fundamentais para a formação do aluno.

As questões 06 e 07 , perguntaram se os estudantes acreditavam que o conhecimento desenvolvido na comunidade contribuía para aprendizagem dos conteúdos ensinados no curso e se existia uma relação entre tais saberes. Na pergunta 06, 100\% dos participantes responderam que sim, os conhecimentos desenvolvidos na comunidade contribuem para aprendizagem de novos conteúdos. E na pergunta 07, 95\% disseram existir, sim, uma relação entre o que aprendeu com a família e os conteúdos aprendidos durante o curso. Vejamos: 
"Sim, pois, algumas coisas que nos foram repassados eu já tinha visto na comunidade como: Plantação de milho, melancia e milho” (PR, 2019).

"Sim, acredito que sim, pois na comunidade vivenciamos a agricultura, a pecuária quando cheguei eu sabia de algumas coisas sobre roças, criações de animais, culturas e época de plantio” (PL, 2019).

"Sim, existe uma relação, por exemplo: a aprendizagem de plantação que foi melhorado aqui no IFRR” (PR, 2019).

"Sim, algumas coisas que minha familia me ensinou eu revir aqui no IFRR. As histórias dos antigos moradores, as culturas da nossa região, as tradições, as plantações, a educação tem uma relação, sim, com o conteúdo do curso" (PL, 2019).

Essas falas sinalizam que existe sim uma relação próxima entre os saberes empíricos dos alunos e os conhecimentos desenvolvidos no curso - o que nos faz compreender que a valorização explícita e constante não ocorra devido à falta de familiaridade dos docentes com as culturas indígenas, sua história e seus saberes.

Nas questões 08, 09 e 10, perguntamos se os estudantes conseguiam visualizar a valorização dos conhecimentos indígenas nas atividades ofertadas pela Instituição. E o que o IFRR poderia fazer para valorizar mais os conhecimentos indígenas dentro do curso. Perguntamos ainda se eles conseguiam aproximar os conteúdos ensinados pelos professores com as atividades desenvolvidas na sua comunidade e como os ensinamentos da comunidade contribuíam na permanência do curso. Para $48 \%$ dos estudantes, o Campus valoriza algumas vezes a cultura indígena, o que acontece somente em eventos promovidos pela instituição. Os que entendem que o Campus valoriza somam 28\%, e para 24\%, não existe valorização da cultura indígena. Com relação à aproximação dos conteúdos, 95\% responderam que sim, conseguem aproximar os conteúdos ensinados pelos professores com as atividades desenvolvidas na sua comunidade, e apenas 5\% disseram não conseguir realizar essa aproximação. No quadro abaixo, apresentamos uma síntese das respostas dos estudantes às perguntas 08, 09, 10 .

Quadro 04 - Valorização dos saberes indígenas na percepção dos estudantes

\begin{tabular}{|l|l|}
\hline Questão & Respostas dos estudantes \\
\hline 08 & "Às vezes. Por mim deveria desenvolver juntamente com os alunos indígenas um projeto \\
& $\begin{array}{l}\text { envolvendo os conhecimentos do aluno junto com os conhecimentos do curso [...]". } \\
\text { "Algumas coisa estão começando a ser valorizada, mais a instituição poderia ofertar }\end{array}$ \\
\hline
\end{tabular}




\begin{tabular}{|c|c|}
\hline & $\begin{array}{l}\text { nos jogos escolares, jogos indígenas [...]”. } \\
\text { "Não. Deveria desenvolver atividades relacionadas ao movimento indígena, fazer e } \\
\text { debater sobre os conhecimentos que o indígena em si possui e compreender como é a } \\
\text { vivência cultural de um indígena". }\end{array}$ \\
\hline 09 & $\begin{array}{l}\text { "Sim. As mesmas aulas de português que estudei na escola anterior aconteceram aqui } \\
\text { no Campus". } \\
\text { "Sim, como exemplo, a matéria de Olericultura, já fazíamos essas práticas há muito } \\
\text { tempo na comunidade com familiares e outras pessoas". } \\
\text { "Não, porque era muito diferente". }\end{array}$ \\
\hline 10 & $\begin{array}{l}\text { "O ensinamento da minha comunidade contribui na parte do trabalho ter uma boa } \\
\text { finalidade, ser organizado isso me ajudou muito durante o estágio". } \\
\text { "Na forma de entender e compreender o que está se passando naquele momento } \\
\text { produtivo de alguma atividade". } \\
\text { "Na parte prática". }\end{array}$ \\
\hline
\end{tabular}

Fonte: Elaboração própria a partir do questionário.

Para 48\% dos estudantes, o Campus valoriza algumas vezes a cultura indígena, o que acontece somente em eventos promovidos pela instituição. Aqui fica claro que o Campus Amajari precisa caminhar rumo a uma educação intercultural, e romper com propostas pedagógicas homogeneizadoras, que restringem a valorização de outros saberes em determinados eventos - afinal, esses estudantes trazem uma bagagem de saberes muito rica que precisa ser visualizada e valorizada em todas as práticas educativas no contexto do curso.

As rodas de conversa, como instrumento, buscaram construir dados a respeito das contribuições e mudanças provocadas nos estudantes indígenas a partir da execução do currículo. O diálogo partiu de um roteiro previamente elaborado, mas durante as conversas os estudantes levantaram outras situações vivenciadas e que, também, contribuíram para compreendermos os processos de ensino e aprendizagem vivenciados por eles.

Segundo os estudantes, o curso contribuiu para promoção de novos conhecimentos, com oferta de disciplinas que proporcionaram muitos aprendizados nas práticas desenvolvidas com suas famílias. As disciplinas técnicas oportunizaram conhecer vários termos científicos atribuídos às práticas que os estudantes já realizavam em suas comunidades, agregando dessa forma - conhecimentos científicos aos saberes e vivências comunitárias. 
A partir desses termos, os estudantes evidenciaram que inicialmente foi difícil compreender o que era ensinado nas disciplinas, pois eles consideravam esses conhecimentos muito distantes da vivência deles, já que não conseguiam fazer uma ligação que fizesse sentido com as atividades já realizadas em sua comunidade. No entanto, aos poucos foram percebendo que as atividades desenvolvidas tinham apenas nomes diferentes, mas o processo de construção era igual ou parecido com as atividades já desenvolvidas com seus familiares. Essa constatação pode ser visualizada na fala de um estudante:

"Solo irrigado nada mais era do que o que eu chamava de 'terra molhada'... Essa ligação foi muito difícil de fazer porque eu não tinha ideia do que era, em minha opinião era apenas 'barro molhado'. Este mesmo participante disse ainda que outra coisa que foi um pouco complicado foi o termo 'coroamento' das plantas, pois para ele “essa era uma relação que simplesmente era apenas fazer um círculo ao redor de cada planta" (RRS, 2019).

Assim, conforme os alunos informaram durante as aulas, os professores falavam vários termos científicos que, em um primeiro momento, pareciam muito distantes das vivências dos estudantes; contudo, eram as mesmas práticas e os mesmos conceitos que os indígenas já conheciam - apenas com nomenclaturas diferentes. Com isso, propomos a construção de um glossário com termos científicos e seus correlatos tradicionais. Esse glossário foi incorporado ao produto educacional.

Os estudantes relataram também sobre a dinâmica do curso como sendo positiva no processo de ensino e aprendizagem, pois o formato do curso em alternância proporciona muitas aulas práticas, porque - além das aulas realizadas na instituição - o tempo comunidade é um momento que eles têm para aplicar o que foi visto em sala de aula. As práticas realizadas no tempo comunidade, segundo os estudantes, são registradas no caderno de vivência, uma ferramenta pedagógica que tem sido uma aliada no processo de aprendizagem. Neste caderno, os alunos descrevem todas as atividades executadas na comunidade. Contudo, os estudantes apontam uma deficiência de prática na área animal, principalmente, práticas com bovinos, criação presente na região e isso, para eles, constituirá um agravante na hora de procurar um emprego no mercado de trabalho. Eles disseram ainda que durante o curso surgiu a ideia de realizarem as práticas em uma fazenda na comunidade, porém não prosperou, pois não havia transporte disponível para o translado, como também não tinha recurso para alimentação dos 
estudantes fora do Campus. Esse apontamento feito pelos alunos nos leva a problematizar se a proposta pedagógica em regime de alternância prevista no PPC tem proporcionado o que diz Ghedin (2012), a saber, o diálogo entre o saber sistematizado e o saber popular em que o educando e a sua realidade (família, propriedade, comunidade) são o foco central do processo ensino-aprendizagem. Ressalta-se que o objetivo dessa proposta é a interação constante entre os fundamentos teóricos, ou seja, a formação científica com a aplicação prática desses fundamentos, conhecimentos por parte do estudante ao longo do seu processo de formação.

Além das contribuições já apontadas, os estudantes, colocaram também que o curso favoreceu a compreensão com relação ao meio ambiente, práticas agrícolas sustentáveis, impactos ambientais que a ação do homem pode ocasionar a partir de técnicas inadequadas. Os estudantes citam a prática do uso do fogo para a limpeza das roças; porém, hoje, depois do curso, esse ato passou a ser repensado. O mesmo acontece com o uso de adubo químico que na percepção dos alunos deve ser evitado, pois é muito prejudicial para solo e saúde humana. Essas reflexões feitas pelos alunos demonstram mudanças sobre algumas práticas desenvolvidas pelos seus. E isso caminha ao encontro da proposta do curso, que é formar técnicos capazes de atuarem como agentes de desenvolvimento sustentável.

No decorrer das conversas, perguntamos sobre a perspectiva de futuro dos estudantes. Nesse momento, percebemos que poucos têm o desejo de permanecer em sua comunidade contribuindo com os conhecimentos adquiridos durante o curso. Isso pode ser visualizado claramente na fala de um estudante:

"Minha perspectiva de futuro é ser um zootecnista muito bem empregado na cidade grande, não devendo mais voltar para a comunidade, até por que no Contão não existe muitas propostas de emprego e isso impede que minha volta seja viável" (JDCS, 2019).

Esse relato nos faz refletir sobre a proposta curricular do curso que tem como objetivo oportunizar a formação de profissionais que poderão intervir na realidade local, buscando superar problemas relacionados à organização social, com conhecimentos voltados à agropecuária, podendo contribuir com o desenvolvimento social e econômico do município e da região. E a partir disso, pensamos sobre o "movimento como ilusão" tratada por Machado (2017), contrapondo à perspectiva prevista na Proposta Pedagógica do Curso. Em torno disso, a ilusão refletida por Machado tem como cerne a terra e o movimento, que segundo o autor: 
[...] opera como uma ideologia "enganosa", que acaba por beneficiar os que não se movimentaram em detrimento daqueles que o fizeram. Tratamos tanto da mobilidade como da imobilidade, portanto quem sai para a cidade não recebe terra, que é o bem mais valorizado nesse contexto. O movimento é literalmente uma expulsão de parte dos membros da família do acesso à terra (MACHADO, 2017, p.29).

Dessa forma, entendemos que a intenção de oportunizar formação de profissionais que poderão intervir na realidade local ainda não foi plenamente atingida.

Outro questionamento que levantamos foi sobre a percepção a respeito da Educação Profissional e Tecnológica. Os estudantes colocaram que visualizam esta modalidade de ensino como uma oportunidade de adquirir novos conhecimentos e se preparar para o mercado de trabalho. Como pode ser visto na fala de um estudante:

"A educação profissional, na minha opinião, é o estudo que traz mais conhecimento e se aprofunda nos conhecimentos já conhecidos e prepara para o mercado de trabalho” (VMT, 2019).

Com isso, constatamos que existe uma percepção sobre a Educação Profissional e Tecnológica por parte dos estudantes, mas esse pensamento em muitos casos está atrelado a uma educação historicamente dividida entre as classes sociais. Em que as minorias padecem com uma educação desprovida de saberes capaz de formar para a vida, restringindo-se a formar, apenas, para o mercado de trabalho.

Ao longo das rodas de conversa, a turma expôs o preconceito sofrido. Os estudantes entendem que o preconceito interfere no processo de ensino e aprendizagem. Segundo eles, por serem indígenas, até naquele momento, continuavam a sofrer preconceitos. A dinâmica do curso também contribuía com essa prática, pelo fato de terem o tempo comunidade. Um estudante descreve o anseio da turma ao dizer que:

"Até os dias de hoje há esse preconceito severo sobre os indigenas, mas nessa afirmação eu pergunto. Porque esse preconceito todo? se lá nos anos de 1500 Pedro Álvares Cabral o tal descobridor do que chamamos, hoje, de Brasil encontrou índio, ou será que ele encontrou holandeses? Norte americanos? ou Ingleses? Não, os portugueses chegaram no Brasil e encontraram indígenas, então com isso tiro uma conclusão que o brasileiro independente do que for é, sim, um indigena" (JDCS, 2019)".

\section{CONSIDERAÇÕES FINAIS}


A investigação possibilitou compreender que a Educação Profissional e Tecnológica ofertada a estudante indígena precisa estar em constante diálogo intercultural com a vivência desses jovens, permitindo que os processos de construção de novos conhecimentos sejam construídos de forma mais fácil e prazerosa fazendo sentido para o estudante desde os primeiros momentos.

Nesse viés, existe uma necessidade urgente de se compreender como os estudantes indígenas constroem e dialogam os conhecimentos dentro da Educação Profissional e Tecnológica. Quais as perspectivas de futuro? Qual a contribuição dos seus aprendizados e conhecimentos para o desenvolvimento regional? Esses questionamentos precisam ser analisados para que o IFRR/Campus Amajari possa subsidiar sua atuação diante de novos desafios, a começar pelas propostas de reformulações dos planos de curso que atualmente não deixa claro a interculturalidade compreendida com possibilidade de respeitar as diferenças e integrá-las em uma unidade que não as anule.

Assim, o estudo evidenciou que a proposta pedagógica atualmente não leva em conta as especificidades indígenas preconizadas pela Educação Escolar Indígena. Entretanto, alguns estudantes disseram conseguir visualizar nos eventos promovidos pela instituição certa valorização de conhecimentos e saberes nativos. Segundo eles, ao convidar grupos indígenas para se apresentarem nos eventos e também, ao expor artesanatos confeccionados pelos indígenas, a escola está de certo modo valorizando a cultura indígena.

Outro dado evidenciado pelos estudantes foi a "deficiência" da formação técnica, no que se refere à área de produção animal pelas poucas atividades no decorrer do curso. Apesar disso, a formação teórica foi considerada positiva pela qualidade dos professores que as ministraram.

A partir dessas considerações, acreditamos que o Campus Amajari enquanto instituição federal de Educação Profissional e Tecnológica precisa romper com a forma de ensino posta hoje e construir estratégias capazes de se aproximar de uma educação intercultural em que haja valorização dos saberes tradicionais, tendo em vista o grande número de estudantes indígenas em seu contexto escolar e social.

\section{REFERÊNCIAS}

BARDIN, Laurence. Análise de conteúdo. Edição Persona. 1977. 
BERGAMASCHI, Maria Aparecida e SILVA, Rosa Helena da. Educação escolar indígena no Brasil: da escola para índios às escolas indígenas. Agora, Santa Cruz do Sul, v. 13, n. 1, p. 124-150, jan./jun. 2007.

BRANDÃO, Carlos Rodrigues; BORGES, Maristela Correa. A pesquisa participante: um momento da educação popular. Ver. Ed. popular, Uberlândia, v.6, p. 51-62. Jan/dez.2007.

BRANDÃO, Carlos Rodrigues; STRECK, Danilo (Org.) . Pesquisa participante: o saber da partilha. Aparecida: Ideias \& Letras, 2006. 295 p .

BRASIL, Congresso Nacional. Constituição: República Federativa do Brasil. Brasília: Ministério da Educação. 1988.

Ministério da Educação e do Desporto. Lei no 9394/96. Lei de Diretrizes e Bases da Educação. Brasília: Congresso Nacional, dezembro, 1996.

. Ministério da Educação e do Desporto. Referencial Curricular Nacional para as Escolas Indígenas. Brasília: MEC; SEF, 1998.

CANDAU, Vera Maria Ferrão; RUSSO, Kelly. INTERCULTURALIDADE E EDUCAÇÃO NA AMÉRICA LATINA: uma construção plural, original e complexa. Rev. Diálogo Educ., Curitiba, v. 10, n. 29, p. 151-169, jan./abr. 2010.

FLEURI, Reinaldo Matias. Intercultura e educação. Rev. Bras. Educ. [online]. 2003, n. 23, pp.16-35.

GHEDIN, Evando. Educação do Campo: epistemologia e prática Evandro Ghedin, (organizador).-1.ed.- São Paulo: Cortez, 2012.

INSTITUTO FEDERAL DE RORAIMA. Plano do curso Técnico em Agropecuária Integrado ao Ensino Médio em Regime de Alternância. Amajari, RR: 2018.

MACHADO, I. R. Movimentos e parentesco: sobre as especificidades dos deslocamentos. Revista Campos, v 15 n. 2, 2017.

MELO, Marcia Cristina Henares de; CRUZ, Gilmar de Carvalho. Roda de conversa: uma proposta metodológica para a construção de um espaço de diálogo no ensino médio. Imagens da Educação, v. 4, n. 2, p. 31-39, 2014.

MOURA, Dante Henrique. Educação Básica e eEducação Profissional e Tecnológica: Dualidade histórica e perspectivas de integração. Holos, vol. 2, 2007.

NASCIMENTO, Raimundo Nonato Ferreira do. Antropologia, Interculturalidade e Educação Escolar Indígena em Roraima. 1ed. Curitiba: Appris, 2017. 
OLIVEIRA, Felipe Nagoberto Coimbra de. O curso Integrado em Agropecuária do IFAM Campus Maués e a formação humana integral: desafios e perspectivas de um Campus do interior do estado do Amazonas. Dissertação. Manaus - AM, Agosto/2019.

RAMOS, Marise Nogueira. A Pedagogia das Competências: autonomia ou adaptação? São Paulo: Cortez, 2001.

RICHARDSON, Roberto Jarry. Pesquisa Social: métodos e técnicas. -3 ed.- 8 reimpr.- São Paulo: Atlas, 2008.

História e política da educação profissional. Coleção Formação Pedágogica, Vol.

V. Curitiba: Instituto Federal do Paraná, 2014.

TASSINARI, Antonella Maria Imperatriz. Escola indígena: novos horizontes teóricos novas fronteiras de educação. In: SILVA, Aracy Lopes da; FERREIRA, Mariana Kawall Leal (Orgs.). Antropologia, história e educação: a questão indígena e a escola. São Paulo: Global, 2001.p. 44-70.

TAVARES, Moacir Gubert. Evolução da Rede Federal de Educação Profissional e Tecnológica: as etapas históricas da Educação Profissional no Brasil. IX ANPEDSULA, 2012. 